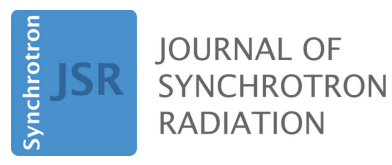

ISSN 1600-5775

Received 10 December 2017

Accepted 18 April 2018

Edited by Y. Amemiya, University of Tokyo, Japan

Keywords: X-ray microtomography; in situ synchrotron X-ray imaging; induction furnace; metals; volcanic rocks; ceramics.

Supporting information: this article has supporting information at journals.iucr.org/s

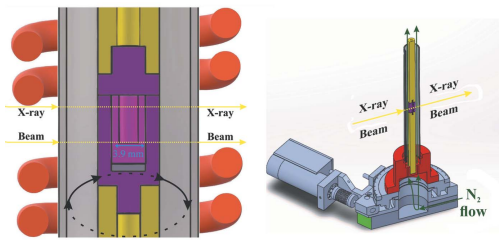

C 2018 International Union of Crystallography

\section{A compact and flexible induction furnace for in situ X-ray microradiograhy and computed microtomography at Elettra: design, characterization and first tests}

\author{
Marko Kudrna Prašek, ${ }^{\text {a,b }}$ Mattia Pistone, ${ }^{\text {c Don R. Baker, }}{ }^{a}$ Nicola Sodini, ${ }^{\text {b }}$ \\ Nicoletta Marinoni, ${ }^{\text {d }}$ Gabriele Lanzafame ${ }^{\mathrm{b}}$ and Lucia Mancini ${ }^{\mathrm{b}}$ *
}

${ }^{\mathbf{a}}$ Earth and Planetary Sciences, McGill University, Montréal, Canada H3A 2A7, ${ }^{\mathbf{b}}$ Elettra-Sincrotrone Trieste SCpA, 34149 Basovizza (Trieste), Italy, 'Institute of Earth Sciences, University of Lausanne (UNIL), CH-1015 Lausanne, Switzerland, and 'Dipartimento di Scienze della Terra 'Ardito Desio', Università degli Studi di Milano, Milano, Italy. *Correspondence e-mail: lucia.mancini@elettra.eu

A compact and versatile induction furnace for in situ high-resolution synchrotron and laboratory hard X-ray microradiography and computed microtomography is described. The furnace can operate from 773 to $1723 \mathrm{~K}$. Its programmable controller enables the user to specify multiple heating and cooling ramp rates as well as variable dwell times at fixed temperatures allowing precise control of heating and cooling rates to within $5 \mathrm{~K}$. The instrument can work under a controlled atmosphere. Thanks to the circular geometry of the induction coils, the heat is homogeneously distributed in the internal volume of the graphite cell $\left(c a .150 \mathrm{~mm}^{3}\right)$ where the sample holder is located. The thermal gradient within the furnace is less than $5 \mathrm{~K}$ over a height of $c a .5 \mathrm{~mm}$. This new furnace design is well suited to the study of melting and solidification processes in geomaterials, ceramics and several metallic alloys, allowing fast heating (tested up to $6.5 \mathrm{~K} \mathrm{~s}^{-1}$ ) and quenching (up to $21 \mathrm{~K} \mathrm{~s}^{-1}$ ) in order to freeze the sample microstructure and chemistry under high-temperature conditions. The sample can be held at high temperatures for several hours, which is essential to follow phenomena with relatively slow dynamics, such as crystallization processes in geomaterials. The utility of the furnace is demonstrated through a few examples of experimental applications performed at the Elettra synchrotron laboratory (Trieste, Italy).

\section{Introduction}

The physical and chemical behaviour of materials such as metals, ceramic alloys and geomaterials at high-temperature and/or high-pressure conditions was traditionally analysed in the quenched final run products at room-temperature conditions after synthesis. The development of certain materials such as foams, compacts in liquid-phase sintering and ceramics requires inherently dynamic processes and full understanding of the processes that generate the materials (i.e. through chemical analysis, mechanical testing, thermal treatment, chemical reactions, etc.). As a result of analytical limitations, our understanding of these dynamic processes is almost exclusively based upon ex situ analyses of the final products rather than analyses of the systems during such processes.

The optical opacity of many materials (both natural and artificial) makes observations in visible light difficult, if not impossible. Therefore, these observations usually have to be performed on thin sections of the sample after the dynamic process is finished or has been interrupted by quenching. Although this procedure has led to many important insights 
and improvements in the materials that we use, this 'snapshot' sampling can provide at most only an incomplete view of spatially and temporally variable systems. Many phenomena still remain unclear because it has been impossible to observe and record the formation processes continuously.

The high-penetrating power of hard X-rays and the advent of new instruments and novel imaging techniques has made microradiography (Miller \& Beech, 1972; Curreri \& Kaukler, 1996; Sen et al., 1997; Li et al., 2006; Rack et al., 2009) and computed microtomography ( $\mu \mathrm{CT}$ ) (Mayo et al., 2012; Fife et al., 2012; Riesch et al., 2013; Maire \& Withers, 2014; Bouttes et al., 2015; De Schryver et al., 2016) unique tools to observe internal structures of materials undergoing processes such as melting, vesiculation, and the growth, dissolution or reaction of crystalline phases. Two-dimensional and three-dimensional $\mathrm{X}$-ray imaging experiments carried out under controlled hightemperature conditions represent the next generation of $i n$ situ time-resolved experimental observations of materials and the processes forming them.

Recently, advancements in technology such as sCMOS detectors, coupled with both fast-response scintillator screens and new X-ray sources, e.g. synchrotron sources producing high-brillance radiation, have stimulated renewed interest in time-resolved investigations (Fife et al., 2012; Daudin et al., 2015; Mokso et al., 2010; 2017; Yu et al., 2017; Zhao et al., 2017). Also, the advent of new laboratory systems able to perform fast microradiography and $\mu \mathrm{CT}$ experiments (Larsson et al., 2011; De Schryver et al., 2016) paved the way for the application of these techniques to novel in situ and real-time studies. The design of an instrument able to perform this kind of study has to be carefully tailored to the technical features of the X-ray imaging system employed.

In earlier experiments, magmatic and volcanic applications have been investigated by synchrotron-based X-ray imaging at high temperatures. The first experiments (Bai et al., 2008) were carried out on the GSECARS beamline in a custom furnace at the Advanced Photon Source of Argonne National Laboratory (USA). An accurate temperature control was obtained by using a $\mathrm{Pt}-\mathrm{Rh} / \mathrm{Pt}$ thermocouple. The employed furnace was well suited for in situ X-ray radiography and for ex situ $\mu \mathrm{CT}$ studies. More recently, in situ $\mu \mathrm{CT}$ experiments were carried out at the TOMCAT beamline of the Swiss Light Source (PSI, Villigen, Switzerland) using a laser furnace system (Fife et al., 2012; Baker et al., 2012; Pistone et al., 2015a,b). This instrument allowed rapid sample heating and the acquisition of ultrafast tomographic scans on a scale of $1 \mathrm{~s}$ or even faster (Baker et al., 2012). The furnace temperature was measured with an optical pyrometer that could not monitor an eventual thermal gradient within the sample holder. Both of these furnaces could operate at temperatures higher than $1500 \mathrm{~K}$ in air (i.e. under non-controlled atmosphere conditions), and using either alumina or boron nitride sample holders, the latter characterized by a high thermal conductivity (20$60 \mathrm{~W} \mathrm{~m}^{-1} \mathrm{~K}^{-1}$ ).

Although these experiments expanded our understanding of dynamic processes at high temperatures, we saw the need for a different furnace design. An important feature of a high- temperature furnace is the ability to work under a controlled atmosphere (Boller et al., 2017), essential when investigating, for instance, samples containing elements with multiple oxidation states (e.g. Fe, Mn, V, S). Moreover, when operating in air, the boron nitride sample holders might oxidize and degrade, especially at temperatures above $1573 \mathrm{~K}$ (Lavrenko $\&$ Alexeev, 1986). A potential issue in the design of a furnace is the size of the hot spot with respect to the sample dimensions. A limited size hot spot can potentially induce thermal gradients both laterally (between sample and holder) and vertically (along the sample). Finally, an accurate monitoring of thermal fluctuations and gradients is an essential requirement.

In this contribution, we present the design and fabrication of a compact and flexible high-temperature induction furnace system for the in situ study of high-temperature processes using both hard X-ray microradiography and $\mu \mathrm{CT}$ techniques. The furnace can work under a controlled atmosphere and can be used to melt geomaterials, ceramics and many metallic alloys at temperatures from 773 to $1723 \mathrm{~K}$.

An accurate control of heating and cooling rates can be achieved and used for material melting (with a heating rate up to $6.5 \mathrm{~K} \mathrm{~s}^{-1}$ as tested so far) and solidification (with a cooling rate up to $21 \mathrm{~K} \mathrm{~s}^{-1}$, to freeze the sample microstructure and chemistry under high-temperature conditions).

This new furnace has been designed and optimized to operate at the SYRMEP beamline of the Elettra synchrotron facility in Basovizza (Trieste, Italy). This beamline is characterized by a photon flux that limits the use of ultrafast hard X-ray $\mu \mathrm{CT}$ (Tromba et al., 2010). Therefore, the furnace has been conceived to investigate dynamic processes characterized by relatively slow kinetics, with microtomographic scan durations on a scale of 60-180 s and microradiography studies on the scale of $0.1-0.5 \mathrm{~s}$ (at the $2.4 \mathrm{GeV}$ mode of the Elettra machine). However, the instrument could be also installed in another hard X-ray $\mu \mathrm{CT}$ beamline with a more brilliant source or even in an open conventional X-ray $\mu \mathrm{CT}$ scanner.

Here, we also provide a few examples to demonstrate the utility and flexibility of this new furnace design.

\section{Furnace design and calibration}

At Elettra, two different facilities are available for hard X-ray imaging: the SYRMEP beamline based on a bending magnet source, and the TomoLab instrument, a custom-developed $\mu \mathrm{CT}$ instrument equipped with a sealed microfocus X-ray source (Polacci et al., 2009; Zandomeneghi et al., 2010). The furnace design was optimized to use the available photon flux, maximum vertical size of the $\mathrm{X}$-ray beam and energy range of the SYRMEP beamline. However, the furnace also can be easily installed in the TomoLab station in order to carry out laboratory-based X-ray microradiography and $\mu \mathrm{CT}$ experiments.

In $\$ \$ 2.1$ and 2.2 the main technical features of the two X-ray facilities at Elettra are described, and in $\$ \S 2.3$ and 2.4 the furnace design and the temperature calibration procedure are detailed. 


\subsection{The SYRMEP beamline setup}

Two different configurations at the SYRMEP beamline (http://www.elettra.eu/elettra-beamlines/syrmep.html) are compatible with the new induction furnace. In the first configuration, a highly coherent and nearly-parallel X-ray beam is delivered by a bending magnet source. The beam has a laminar shape with a maximum size of $220 \mathrm{~mm}(\mathrm{~h})$ by $6 \mathrm{~mm}$ (v). The energy of the X-ray beam is tuned to the sample material through a double-crystal $\mathrm{Si}(111)$ monochromator between 8.3 and $40 \mathrm{keV}$. The sample is located at $c a .24 \mathrm{~m}$ from the X-ray source. Sample projections are typically recorded over a total scan angle of $180^{\circ}$ by a CCD camera coupled to a Gadox scintillator screen by a fiber optic taper. In the second configuration, $\mathrm{X}$-ray $\mu \mathrm{CT}$ experiments are carried out in white-beam mode. The sample is located at $c a .16 \mathrm{~m}$ from the source and the maximum beam size at the sample is $160 \mathrm{~mm}(\mathrm{~h}) \times 4 \mathrm{~mm}(\mathrm{v})$. In this configuration, images are acquired using a microscope system based on a 16-bit, $2048 \times$ 2048 pixel, water-cooled sCMOS detector coupled with a $17 \mu \mathrm{m}$-thick LSO:Tb scintillator screen. The X-ray beam is filtered ('pink beam') to select a mean energy in the X-ray spectrum optimized for the specific sample of interest. Using polychromatic radiation allows higher photon flux and thus decreases the scan duration of $\mu \mathrm{CT}$ experiments. Furthermore, such a setup is ideal for the sCMOS detector, which has the capability to acquire and read out individual projections at rates that are orders of magnitude faster than the traditional CCD cameras. For both configurations, experiments were performed in propagation-based phase-contrast mode (Cloetens et al., 1997; Polacci et al., 2010).

When performing dynamic $\mu \mathrm{CT}$ experiments a compromise between the number of projections, exposure time per projection and final image quality is needed. The selection of these parameters is strongly affected by the type of sample (material, microstructure, texture) and on the specific physical properties we wish to investigate. At SYRMEP, using a mean energy of $24 \mathrm{keV}$, it has been possible to obtain a 'good' image quality with an exposure time per projection of the order of $0.2 \mathrm{~s}$ (at the $2.4 \mathrm{GeV}$ mode of the Elettra machine) producing a scan duration of $180 \mathrm{~s}$ if 900 projections are acquired. The scan duration can be reduced if a weakly absorbing sample is investigated under high-temperature conditions and the mean energy is set in a range of $10-15 \mathrm{keV}$ (highest flux region), or by reducing the number of projections per scan. At present, the setup is mechanically limited by the maximum speed of the rotation stage to a minimum acquisition time for a full threedimensional data set acquisition of 35 s. In July 2018 a new airbearing rotation stage will be installed at SYRMEP that will remove this limitation.

\subsection{The TomoLab instrument setup}

The TomoLab station complements the SYRMEP beamline in terms of energy range and vertical beam size (http://www. elettra.eu/lightsources/labs-and-services/tomolab/tomolab. $\mathrm{html}$ ). The X-ray source can operate in a voltage range from 40 to $130 \mathrm{kV}$, with a maximum current of $300 \mu \mathrm{A}$ and a minimum focal spot of $5 \mu \mathrm{m}$. The most-used detector is a 12 bit, water-cooled, $4008 \times 2672$ pixel CCD camera consisting of a full-frame CCD imager coupled to a Gadox scintillator by a fiber-optic taper. The effective pixel size of the detector is $12.5 \mu \mathrm{m} \times 12.5 \mu \mathrm{m}$ corresponding to a maximum field of view of $50 \mathrm{~mm}(\mathrm{~h}) \times 33 \mathrm{~mm}(\mathrm{v})$. Exploiting the magnification effect offered by the cone-beam geometry (Feldkamp et al., 1984), the source-to-sample and source-to-detector distances can be varied over a range of $c a .1 .5 \mathrm{~m}$ in order to achieve a spatial resolution close to the focal spot size of the source and to work both in absorption and propagation-based phase-contrast mode (Wilkins et al., 1996; Zandomeneghi et al., 2010). Being an open instrument, different types of detectors can be easily installed.

\subsection{Furnace design}

The furnace developed at Elettra for synchrotron X-ray $\mu \mathrm{CT}$ imaging is based on the principle of the Oersted effect: an electrically conducting object can be heated by electromagnetic induction through heat generated in the object by the application of a radiofrequency signal (Brown et al., 1947). An important feature of the induction heating process is that the heat is generated inside the object itself, instead of by an external heat source. Thus, samples can be heated or solidified very rapidly; the process is easily controlled and there is no need for external electrical contacts.

Fig. 1(a) schematically shows the design of the Elettra furnace, which is composed of the heating element, the graphite cylindrical shell containing the sample holder or crucible, two zirconia rods directly connected to the upper and lower end of the graphite shell, and a quartz tube surrounding the graphite shell and the zirconia rods. The heating element of the furnace is an induction coil controlled by a HGT-1200/ $0.45 \mathrm{~N}$ high-frequency generator produced by Linn High

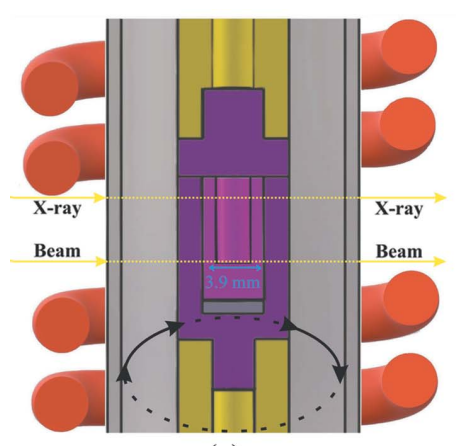

(a)

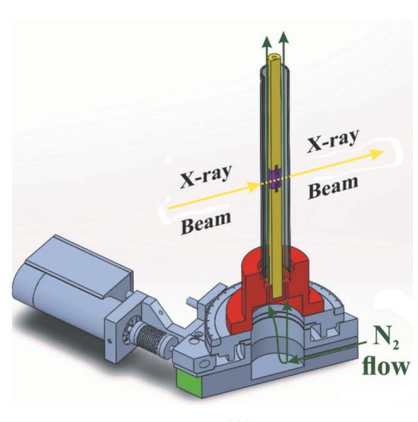

(b)

\section{Figure 1}

(a) A schematic view of the furnace assembly. This does not show the upper hollow zirconia rod holding the thermocouple used for monitoring the temperature during experiments. The quartz glass tube channels the nitrogen gas injected into the bottom of the furnace and is used to prevent oxidation of the graphite susceptor at high temperatures. The X-ray beam passes through the target location to be imaged (i.e. sample in the graphite susceptor) without encountering the induction coils (in red). The curvilinear black arrows indicate the rotating part of the setup during X-ray tomographic experiments (induction coils are fixed). (b) The custom-designed (at Elettra) sample holder that allows continuous sample rotation while the gas delivery system is stationary. 
Therm GmbH company (Germany). The cylindrical geometry of the coil ensures uniform distribution of heat around the sample. Moreover, the choice of a vertical arrangement of the coil generates a large hot spot for the sample and is compatible with the geometry of a CT experiment. The coil shape has been customized in order to keep a $6 \mathrm{~mm}$-high region 'coilfree' and a uniform hot spot ( $<5 \mathrm{~K}$ variation) within the internal volume of the graphite shell traversed by the X-ray beam.

In addition to the desired flexibility in controlled rates of heating, cooling and temperature gradient, an important requirement is that the furnace interferes as little as possible with the X-ray path, which is essential for $\mu \mathrm{CT}$ experiments. Indeed, X-rays should pass through a sample and reach the detector with a minimum attenuation caused by the furnace. Graphite was chosen as the susceptor for the furnace because of its low X-ray absorption coefficient. With the different materials selected for the furnace construction, the X-ray transmission is $c a .67 \%$ at an energy of $24 \mathrm{keV}$ in the absence of a crucible.

For the experiments reported in this contribution, we used an alumina crucible with an internal diameter of $3.9 \mathrm{~mm}$ and an internal vertical size of $7 \mathrm{~mm}$. This material was selected for its chemical and thermal stability as well as its reasonable transmission of X-rays at energies above $20 \mathrm{keV}$ (the crucible has an X-ray transmission of about $62 \%$ at $24 \mathrm{keV}$ ). Alumina also has a moderate thermal conductivity $\left(5.43 \mathrm{~W} \mathrm{~m}^{-1} \mathrm{~K}^{-1}\right.$ at $1673 \mathrm{~K}$ ) ensuring heat transfer to the sample, and can be reliably used up to temperatures of $1873 \mathrm{~K}$. Other materials such as boron nitride ( $\mathrm{ca} 94 \%$ of $\mathrm{X}$-ray transmission at $24 \mathrm{keV}$ ) could be selected for the crucible depending on the specific scientific application and temperature. The alumina crucible, zirconia rods and graphite shell were manufactured by the INTELLION company (France).

The quartz tube surrounding the graphite shell and the zirconia rods allows a continuous flux of nitrogen gas that minimizes the amount of ambient air around the graphite components of the furnace to prevent the oxidation of the graphite susceptor at high temperatures. In principle, different gases and/or gas mixtures can be injected in the quartz tube allowing observations in a controlled atmosphere. In order to investigate the possibility of controlling the oxygen fugacity $\left(\mathrm{fO}_{2}\right)$ in the furnace, glasses of basaltic composition [48.89 wt $\% \mathrm{SiO}_{2}$ and a total iron oxide $\left(\mathrm{FeO}+\mathrm{Fe}_{2} \mathrm{O}_{3}\right)$ concentration of $10.57 \mathrm{wt} \%$ ] were fused at $1573 \mathrm{~K}$ for $4 \mathrm{~h}$. If the oxygen fugacity in the furnace is controlled by oxidation of the graphite susceptor to carbon monoxide, then ferric and ferrous iron in the melt will be reduced to form Fe metal and the sample will become magnetic; but after the experiment the sample was not magnetic. Although we have no direct measurement of the oxygen fugacity, this test is consistent with an estimated oxygen fugacity of $10^{-3}$ for a melt in the presence of $\mathrm{N}_{2}$ gas flowing through the furnace (Nafziger et al., 1971). This test indicates the possibility of controlling the $\mathrm{fO}_{2}$ by traditional mixing of gases such as $\mathrm{CO}_{2}-\mathrm{CO}$ or $\mathrm{CO}_{2}-\mathrm{H}_{2}$ (Nafziger et al., 1971). For example, at $1273 \mathrm{~K}$ we should be able to vary the oxygen fugacity in the furnace from $10^{-18}$ to

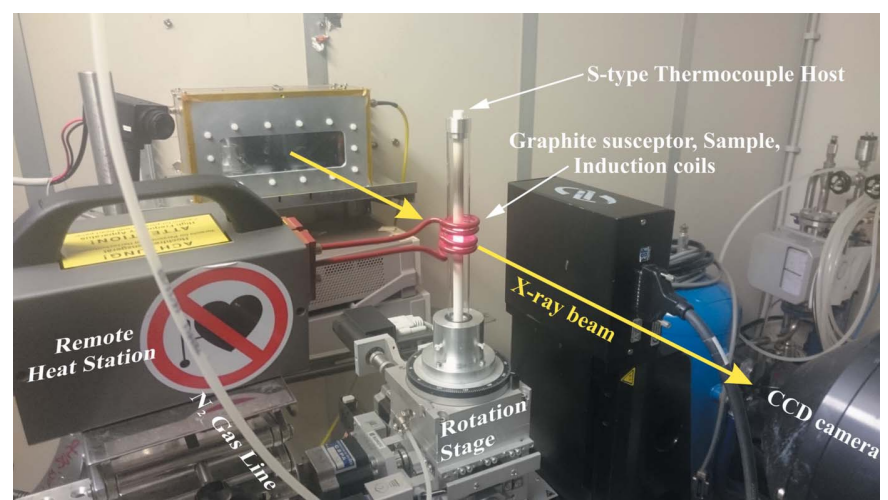

Figure 2

Image showing an overview of the experimental setup used with the induction furnace in operation for in situ measurements as installed at the SYRMEP beamline of Elettra.

$10^{-6}$ by using differing mixtures of $\mathrm{CO}_{2}$ and $\mathrm{CO}$ (Deines et al., 1974). A more detailed study focused on oxygen fugacity control in the furnace will be performed in the near future.

A metallic support, designed and manufactured at Elettra, holds the quartz tube and the zirconia rod at the base of the furnace and allows the gas injection (see Fig. 1b). This support can be directly screwed into the centre of the high-resolution rotation stage of the $\mu \mathrm{CT}$ apparatus on both the SYRMEP beamline and the TomoLab station. The hot spot is approximately $140 \mathrm{~mm}$ above the rotation stage ensuring that temperature-sensitive micromechanical parts are kept at room temperature.

Fig. 2 shows the furnace in operation installed in the experimental hutch of the SYRMEP beamline. During experiments, the power supply and the furnace are set inside the X-ray hutch. The instrument is interfaced to the computer allowing the remote control of the furnace via an RS-232 communication port. Customized control software for maintaining the temperature of interest as well as controlling the rates of heating and cooling is currently under development at Elettra.

\subsection{Temperature control and calibration}

Temperature control is performed by increasing or decreasing the amperage (power) of the high-frequency generator either manually or via the software control. Before the experiments, the furnace is heated to the desired temperature levels with the S-type $\mathrm{Pt}-\mathrm{Rh} / \mathrm{Pt}$ thermocouple positioned vertically inside the crucible instead of the sample (in contact with its internal base) and in the same location. The temperature values were measured by using a FLUKE 54 II temperature controller. The temperature is measured for the corresponding amperage in order to build a calibration curve similar to the one in Fig. 3, which is then used during real experiments to control the temperature by varying the amperage.

For in situ $\mu \mathrm{CT}$ experiments, a continuous sample rotation over $360^{\circ}$ is required and thus the quartz tube and all of the 


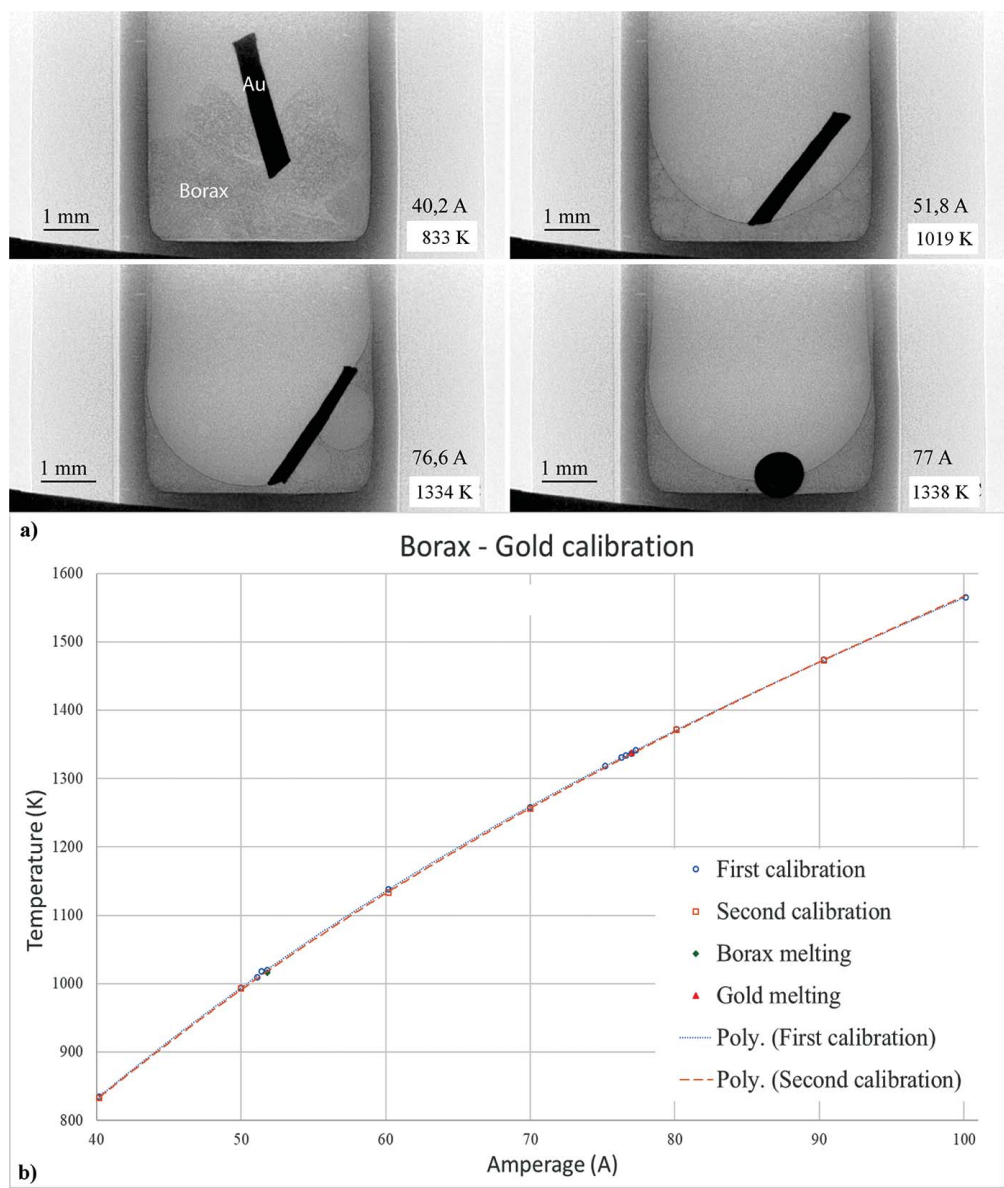

Figure 3

(a) A selection of radiographic images and $(b)$ the corresponding temperature calibration curve at ambient pressure using materials with known melting points: Borax $\left(\mathrm{Na}_{2} \mathrm{~B}_{4} \mathrm{O}_{7} ; 1020 \mathrm{~K}\right.$; green diamonds) and $\mathrm{Au}(1337 \mathrm{~K}$; red triangles). Empty blue circles and empty orange squares indicate temperature readings during two different calibrations at the SYRMEP beamline. Temperature uncertainty is $\pm 5 \mathrm{~K}$ and is the size of the symbols.

components it surrounds rotate during X-ray image acquisition as well. Plastic tubes used for $\mathrm{N}_{2}$ flow into the quartz tube are connected to the metallic support described above (Fig. 1b). The support in Fig. 1(b) allows continuous rotation of the sample while the connected gas inlet and outlet tubes remain stationary. The thermocouple is removed during sample rotation; however, temperature calibration is conducted prior to and after each experimental run or when any furnace component is replaced or modified. The calibration procedure prior to in situ experiments is always conducted with the X-ray beam illuminating the furnace. It is essential to take into account furnace heating by the beam itself, especially when working in white or pink beam mode.

A temperature calibration prior to experiments was also performed by melting standard materials with known melting points. The first calibration experiment was performed on the SYRMEP beamline in monochromatic beam mode using anhydrous Borax $\left(\mathrm{Na}_{2} \mathrm{~B}_{4} \mathrm{O}_{7}\right.$; melting point at $\left.1020 \mathrm{~K}\right)$ and gold foil (melting point at $1337 \mathrm{~K}$ ). The phase transition from solid to liquid of each material was monitored using in situ X-ray microradiography. Images were acquired by a watercooled, 12-bit, $4008 \times 2672$ pixel CCD camera under the following conditions: energy $=24 \mathrm{keV}$, sampleto-detector distance $=350 \mathrm{~mm}$, exposure time per projection $=3 \mathrm{~s}(2.0 \mathrm{GeV}$ mode at Elettra $)$, binning = $2 \times 2$, effective pixel size $=9.0 \mu \mathrm{m}$.

A selection of radiographic images and the corresponding calibration curve are shown in Figs. 3(a) and $3(b)$, respectively: the first calibration (blue circles) was performed from 773 to $1673 \mathrm{~K}$; the second calibration (orange squares) was performed to check for temperature hysteresis between different heating and cooling cycles. Both calibrations are in good agreement with an uncertainty of $\pm 5 \mathrm{~K}$ at the melting points of Borax and $\mathrm{Au}$, respectively. A movie containing the full radiographic sequence during a calibration is reported in the supporting information (see Movie S1).

Temperature calibration using standard materials was also performed by in situ X-ray microradiography in the TomoLab station. In addition to Borax and $\mathrm{Au}$ foil, a cube-shaped $\mathrm{Cu}$ sample (melting point at $1358 \mathrm{~K}$ ) was used. The melting of each material was monitored using in situ $\mathrm{X}$-ray microradiography under the following conditions: sourceto-sample distance $=260 \mathrm{~mm}$, source-to-detector distance $=600 \mathrm{~mm}$, voltage $=70 \mathrm{kV}$, current $=$ $113 \mu \mathrm{A}$, filter $=0.5 \mathrm{~mm} \mathrm{Al}$, exposure time per projection $=4 \mathrm{~s}$, binning $=5 \times 5$ and effective pixel size $=27.2 \mu \mathrm{m}$. A selection of radiographic images and the corresponding calibration curve are shown in Figs. $\mathrm{S} 1(a)$ and $\mathrm{S} 1(b)$ of the supporting information, respectively. There is a movie containing the full radiographic sequence during a calibration reported in the supporting information (see Movie S2).

A calibration test was also conducted ex situ, when the furnace was not installed on the rotation stage, using two S-type thermocouples (both connected to the FLUKE 54 II controller) and a different support setup. A top thermocouple was inserted into the sample holder, the second was placed within the hollow zirconia rod at the base of the sample holder. The distance between the two thermocouples was $c a .3 \mathrm{~mm}$. The aim of this test was to determine the thermal gradient within the crucible by measuring the temperature difference between the top and bottom thermocouples and the real temperature of the sample contained in the crucible. Some fluctuations of the calibration curves were observed caused by a loose contact between the thermocouple bead and the base of the crucible. The geometry of the graphite cell (Fig. 1a), and therefore the heating, is different from the centre of the cell where the crucible is located and where the magnetic field is designed to be homogeneous. In order to circumvent this problem we repeated the calibration, moving the crucible vertically $(c a .5 \mathrm{~mm})$ with only one thermocouple inserted. Combining the results of both procedures, a thermal gradient within the crucible of less than $5 \mathrm{~K}$ over a height of ca. $5 \mathrm{~mm}$ was estimated. 


\section{Experiments}

We selected two representative samples from the fields of material and Earth sciences in order to demonstrate the applicability of the furnace and unravel the dynamic processes that lead to the formation of sample textures. Specifically, vesiculation and crystallization processes in synthetic rocks and ceramic samples were investigated by in situ two-dimensional and three-dimensional X-ray imaging. An ex situ experiment on the synthetic rock sample was also performed.

\subsection{Sample description and preparation}

The ceramic material (sample CD1) investigated was a mixture of clay minerals, feldspar and quartz. This composition represents the foundation of much of the traditional ceramic technology (Carty \& Senapati, 1998). In particular, clays provide plasticity to the green body and are dominated by kaolinite with a lower amount of smectite, montmorillonite, illite, quartz and an organic fraction (Standard Definition of Terms Related to Ceramic Whitewares and Related Products 1996). Feldspar acts as a flux, promoting fusion of the raw materials upon heating, whereas quartz plays the role of a filler, which generally constitutes the coarsest particles in a green body and prevents fired ceramic bodies from shrinking, warping and sagging (Marinoni et al., 2011). In this preliminary study, our attention is focused on pore growth during the firing process of a ceramic body. Distribution, size and type of pores/voids are key features affecting ceramic durability in terms of chemical and physical resistance (Bernasconi et al., 2012, 2014).

A parallelepiped-shaped sample (section of $c a .2 .5 \mathrm{~mm} \times$ $2.5 \mathrm{~mm}$ and $c a .3 \mathrm{~mm}$ in height) was cut out from a larger specimen and inserted in the alumina crucible.

A synthetic rock (sample F60) was prepared from previously melted hydrous $\left(4.2 \mathrm{wt} \% \mathrm{H}_{2} \mathrm{O}\right)$ dacite glass mixed with an aliquot of $60 \mathrm{vol} \%$ quartz crystals (average size = $68 \mu \mathrm{m}$ ), simulating crystal-rich volcanic rocks. Sample preparation, synthesis and characterization of such a material are described in detail by Pistone et al. (2017). Two cylindrical samples (F60a and F60b), each with a diameter of ca. $2.6 \mathrm{~mm}$ and height of $c a .3 \mathrm{~mm}$, were prepared. Each sample was mounted in an alumina crucible.

\subsection{Experimental protocol for the ceramic sample CD1}

Sintering of sample CD1 was explored using the phasecontrast $\mu \mathrm{CT}$ setup configuration in white beam mode at SYRMEP. Six $\mu C T$ scans were recorded, one at room temperature, four during heating of the sample at 923, 1273, 1473 and $1513 \mathrm{~K}$ [using heating increments of $10 \mathrm{~A}$ at each step following the calibration curve reported in Fig. 3(b)], and a final one after quenching to room temperature (switching off the temperature controller). At each high-temperature step, the temperature was kept constant for 10 min [except for the last step $(1513 \mathrm{~K})$, where the temperature was kept constant for $2 \mathrm{~min}$ ] in order to initiate the chemo-physical process and allow the sample to reach textural stability; after this time the $\mu \mathrm{CT}$ scan was performed. This procedure avoids acquisition during highly dynamic phase transitions and sample movement that could have led to blurred X-ray images. For each $\mu \mathrm{CT}$ scan, a set of 1000 projections was acquired over an angular range of $180^{\circ}$. The exposure time per projection was $0.5 \mathrm{~s}$ ( $2.4 \mathrm{GeV}$ mode of Elettra) and the total duration of each $\mu \mathrm{CT}$ scan was $500 \mathrm{~s}$. An effective pixel size of $2.4 \mu \mathrm{m}$ was set for the sCMOS detector placed at $200 \mathrm{~mm}$ from the sample.

The software suite Syrmep Tomo Project (STP; Brun et al., 2015 ; 2017) was used to reconstruct two-dimensional axial slices from the sample projections applying the filtered backprojection algorithm (Herman, 1980; Kak \& Slaney, 1988). Before image reconstruction, a single-distance phase retrieval algorithm was applied to the projection images (Paganin et al., 2002) using the $S T P$ software and setting the $\delta / \beta$ ratio to 70.

\subsection{Experimental protocol for the synthetic rock sample $\mathbf{F} 60$}

Sample F60a was investigated using the white-beam configuration available at SYRMEP for phase-contrast microradiography and $\mu \mathrm{CT}$ experiments. The $\mathrm{X}$-ray beam was filtered by $1.5 \mathrm{~mm}$ of $\mathrm{Si}+1.0 \mathrm{~mm}$ of $\mathrm{Al}$, corresponding to a spectrum with a mean X-ray energy of $c a .25 \mathrm{keV}$. The sampleto-detector distance was set to $200 \mathrm{~mm}$; with these conditions, low-noise individual sample projections with $2.4 \mu \mathrm{m}$ pixel edge-lengths were captured in $2 \mathrm{~s}$ at the $2.0 \mathrm{GeV}$ mode of Elettra.

The vesiculation of the sample at different temperatures (1073, 1373 and $1673 \mathrm{~K})$ was achieved using incremental heating [10 A per step following the calibration curve in Fig. 3(b)]. As experiments were carried out at room pressure, heating these hydrous samples synthesized at $68 \mathrm{MPa}$ triggered water exsolution and bubble formation (Pistone et al., 2017). The sample was held at each temperature step for a time interval of $2 \mathrm{~min}$ and at the maximum temperature for $10 \mathrm{~min}$ before quenching. During the different stages of sample heating and quenching, sequences of in situ X-ray microradiographs were acquired.

Additionally, at each quenched step from the specified temperature a $\mu \mathrm{CT}$ scan (a set of 900 projections over an angular scan of $180^{\circ}$, scan duration $30 \mathrm{~min}$ ) was recorded $10 \mathrm{~min}$ after quenching. The Paganin algorithm with a constant $\delta / \beta$ ratio equal to 80 was applied prior to the reconstruction by using the $S T P$ software.

Sample F60b was investigated by in situ microradiography and $e x$ situ $\mu \mathrm{CT}$ experiments at the TomoLab station following the same temperature ramps described for sample F60a, and following the calibration curve in Fig. S1(a) of the supporting information. In particular, ex situ $\mu \mathrm{CT}$ scans were acquired with identical thermal histories to those on SYRMEP, but after each high temperature ramp followed by quenching it was necessary to dismount the crucible containing the sample from the furnace and install it on the rotation stage in the TomoLab. The following $\mu \mathrm{CT}$ conditions were used for the scans: voltage $=50 \mathrm{kV}$, current $=160 \mu \mathrm{A}$, filter $=0.25 \mathrm{~mm} \mathrm{Al}$, exposure time per projection $=7 \mathrm{~s}$, total scan duration $=3.5 \mathrm{~h}$ ). In combination with the $2 \times 2$ binning applied to the CCD camera pixels, the source-sample and source-detector 
distances were set to 80 and $400 \mathrm{~mm}$, respectively, in order to acquire images at an effective pixel size of $5 \mu \mathrm{m}$; 1800 tomographic projections were acquired in an angular range of $360^{\circ}$ and a set of two-dimensional axial slices was reconstructed with the commercial software $C O B R A$ (Exxim, USA). Ring artefacts in the reconstructed slices were reduced with an algorithm custom-implemented in the Pore $3 D$ software library (Brun et al., 2010).

\section{Results and discussion of the investigated samples}

In this section, the main results obtained for the three samples described in $\S 3$ will be reported and illustrated through both two-dimensional images and three-dimensional views of the samples. For all samples, the two-dimensional images (microradiographs and reconstructed slices) were visualized in the freeware Fiji (Schindelin et al., 2012) while the commercial software VGStudio MAX 2.0 (Volume Graphics, Germany) was employed for the volume renderings.

\subsection{Results on the ceramic sample CD1}

In Fig. 4, a reconstructed two-dimensional axial slice of sample CD1 prior to heating is displayed together with a zoomed region of interest (outlined by the yellow rectangle). The green body consists of feldspar and angular quartz crystals randomly distributed in a clay matrix mainly composed of kaolinite and illite. The clay fractions occasionally agglomerate leading to visible rounded aggregates. Figs. 5(a) and 5(d) provide, respectively, a volume rendering of the whole sample within the crucible and the pore distribution in a selected volume of interest $(300 \times 300 \times 300$ voxel space $)$ prior to heating, extracted by the Pore $3 D$ software after a threedimensional automatic Otsu thresholding. The pores are a few micrometres in size and are randomly dispersed in the matrix and/or at the boundary between crystals and matrix; they are interpreted as air bubbles entrapped during sample preparation. A total porosity of $c a$. 0.5 vol\% was computed.

At $923 \mathrm{~K}$, although the total porosity of the sample is still quite similar to that of the non-heated sample, we observed the development of interconnected pores that can be attributed to the dehydroxylation reactions of kaolinite and lead to a more global porous structure. On the other hand, a limited expansion of the whole sample is observed and can be attributed to several phenomena such as loss of adsorbed water, allotropic transformation of $\alpha$ to $\beta$ quartz, etc. Note that such a transformation induces a volume increase of about $2 \%$ (Singer \& Singer, 1963; Celik, 2010).

At $1373 \mathrm{~K}$, melting of the clay fraction begins with the formation of a liquid phase, as highlighted in Fig. 4, where the rounded clay aggregates apparently dissolve away. Conversely, no relevant reaction takes place involving filler and flux components which maintain their original microstructure (grain size and shape). The appearance of a liquid phase induces a shrinkage of the sample and a decrease of the total porosity. In particular, the smallest pores disappear whereas the largest still remain as isolated structures in the resulting ceramic.

At $1473 \mathrm{~K}$, quartz and feldspar crystals disappear (see Fig. 4) because they melt and the amount of the liquid phase increases. This phase penetrates into the pores, closing and isolating even the largest pores. A shrinkage of the sample of $\sim 8 \%$ was measured (Fig. $5 b$ ) with a total porosity of

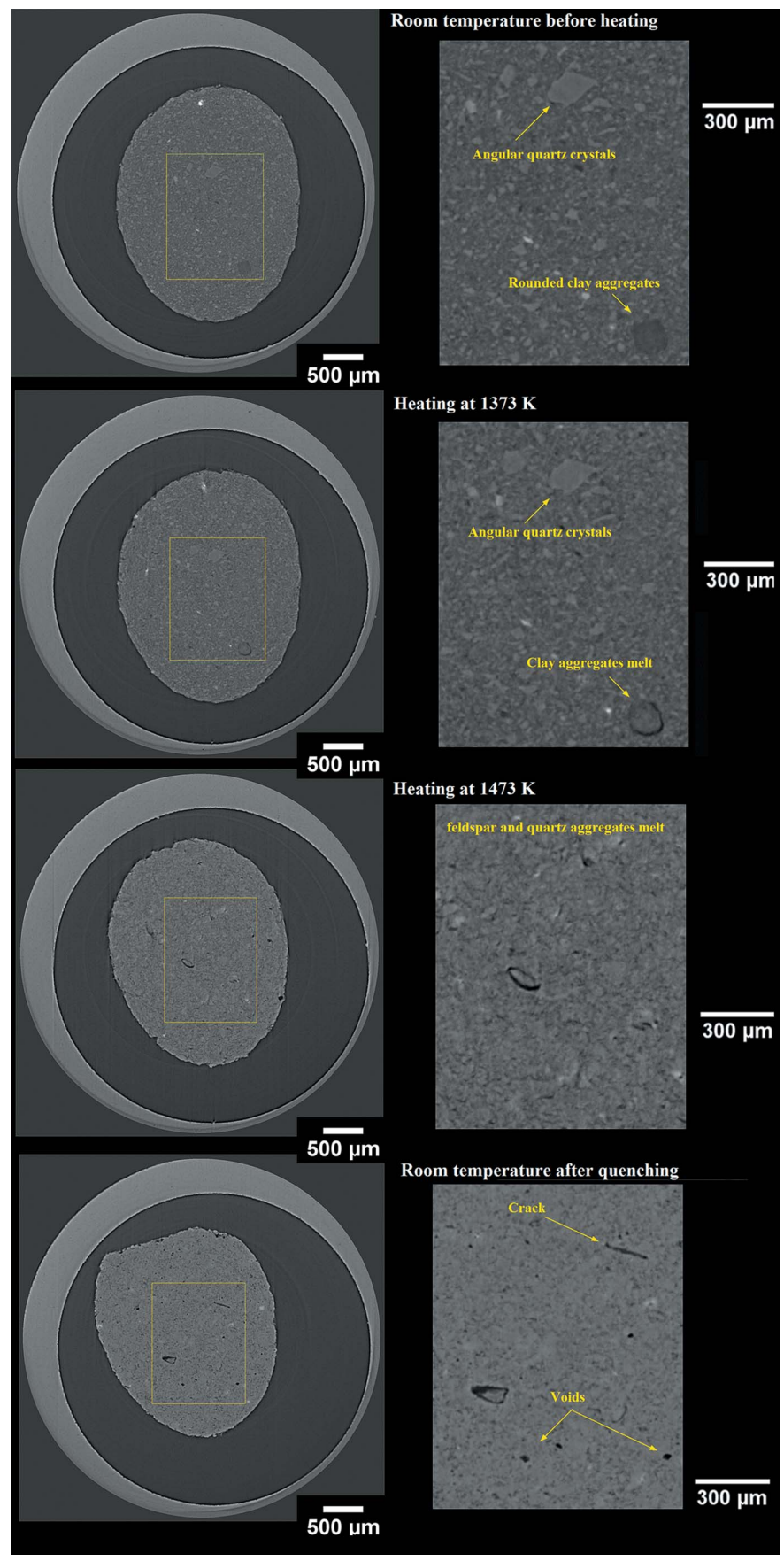

Figure 4

Reconstructed axial slices (left column) and a selected region of interest corresponding to the yellow rectangle (right column) of sample CD1 after experiments performed at room temperature before heating, during heating at $1373 \mathrm{~K}$ and $1473 \mathrm{~K}$, and at room temperature after quenching from $1513 \mathrm{~K}$. Arrows indicate features representative of textural changes. 


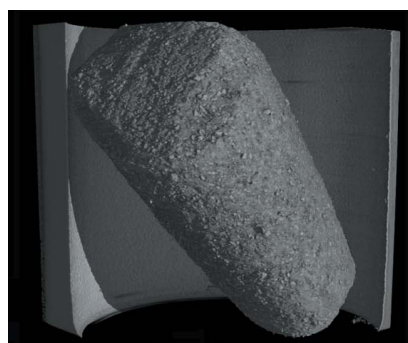

(a)

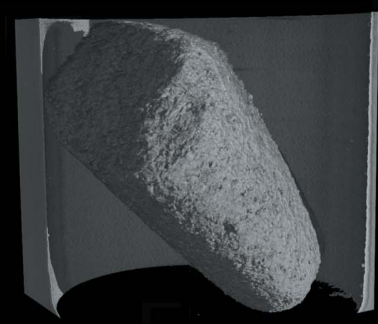

(b)

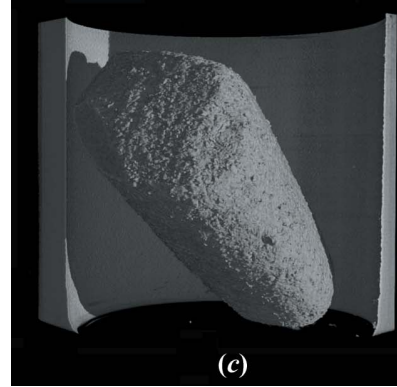

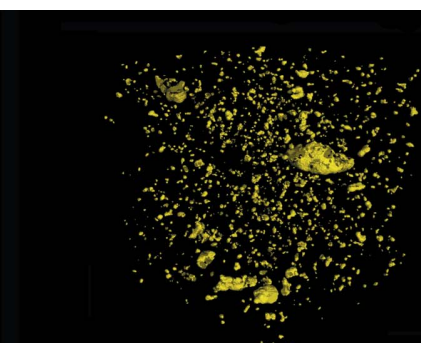

(d)
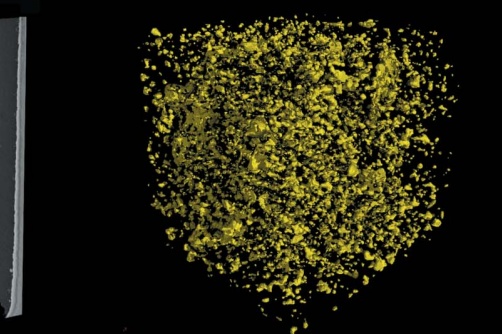

(e)

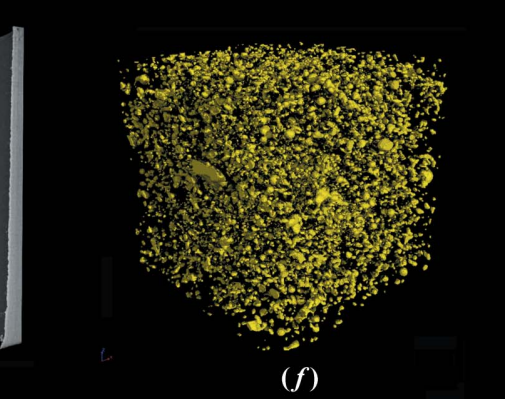

Figure 5

Three-dimensional renderings of sample CD1 at room temperature before heating, at $1473 \mathrm{~K}$, and at room temperature after quenching from $1513 \mathrm{~K}$; panels $(a),(b)$ and $(c)$ show the whole sample within the crucible; in panels $(d),(e)$ and $(f)$ the segmented pore phase (in yellow) in a selected volume of interest $(300 \times 300 \times 300$ voxel space $)$ is represented.

$\sim 1.6$ vol\%. In Fig. 5(e), a volume rendering of the pore distribution is shown. The same is observed at $1513 \mathrm{~K}$, where the original interconnected porosity evolves into a more compact matrix containing isolated and closed spherical pores of $15-20 \mu \mathrm{m}$ in diameter which can be attributed to overfiring conditions.

After firing, the ceramic body appears as a dense structure, which results from a sequence of intracrystalline (regarding a single crystalline/amorphous phase) and intercrystalline (involving more than one crystalline/amorphous phase) reactions (Gualtieri, 2007).

Focusing our attention on the ceramic microstructure after quenching from $1513 \mathrm{~K}$, a porosity of $\sim 3$ vol\% was determined and is characterized by spherical pores, which are a few micrometres in size and are mostly isolated (see Figs. 4 and $5 f$ ). A few microcracks around the quartz crystals are also observed. The final ceramic shrinkage is $\sim 10 \%$ (Fig. $5 c$ ).

The results presented highlight the power of the in situ experiments for exploring the firing process of ceramic materials. In particular, the possibility of following the growth/ development of pores in real time, which play a key role in the technological performance of a ceramic body, as well as the appearance of the melt fraction upon heating, provides fundamental information for the optimization of the ceramic firing process.

\subsection{Results on the synthetic rock sample F60}

A region of interest selected from two-dimensional axial slices in the central part of sample F60a after quenching at different temperatures is shown in Fig. 6; the corresponding three-dimensional renderings, cropped from the analysed volumes as in Fig. 6, are displayed in Fig. 7. The in situ experiments captured a multistage sequence of vesiculation and outgassing that natural magmas may experience during their rise and eruption prior to fragmentation: nucleation and growth of bubbles from room temperature (Figs. $6 a, 7 a$ ) up to $1073 \mathrm{~K}$ (Figs. 6b, 7b); volume inflation and initial bubble coalescence in the temperature range of 1073-1373 K (Figs. $6 c$, $7 c$ ); and bubble coalescence and outgassing leading to sample contraction from 1373 to $1673 \mathrm{~K}$ (Figs. 6d, 7d).

A similar behaviour was observed in sample F60b at lower spatial resolution and with much longer scanning times (see details in \$3.3) during ex situ conventional X-ray $\mu \mathrm{CT}$ experiments performed at the TomoLab station of Elettra (Fig. S2 of the supporting information).

These results are suggestive of how the viscosity of the silicic melt surrounding gas bubbles decreases with tempera-

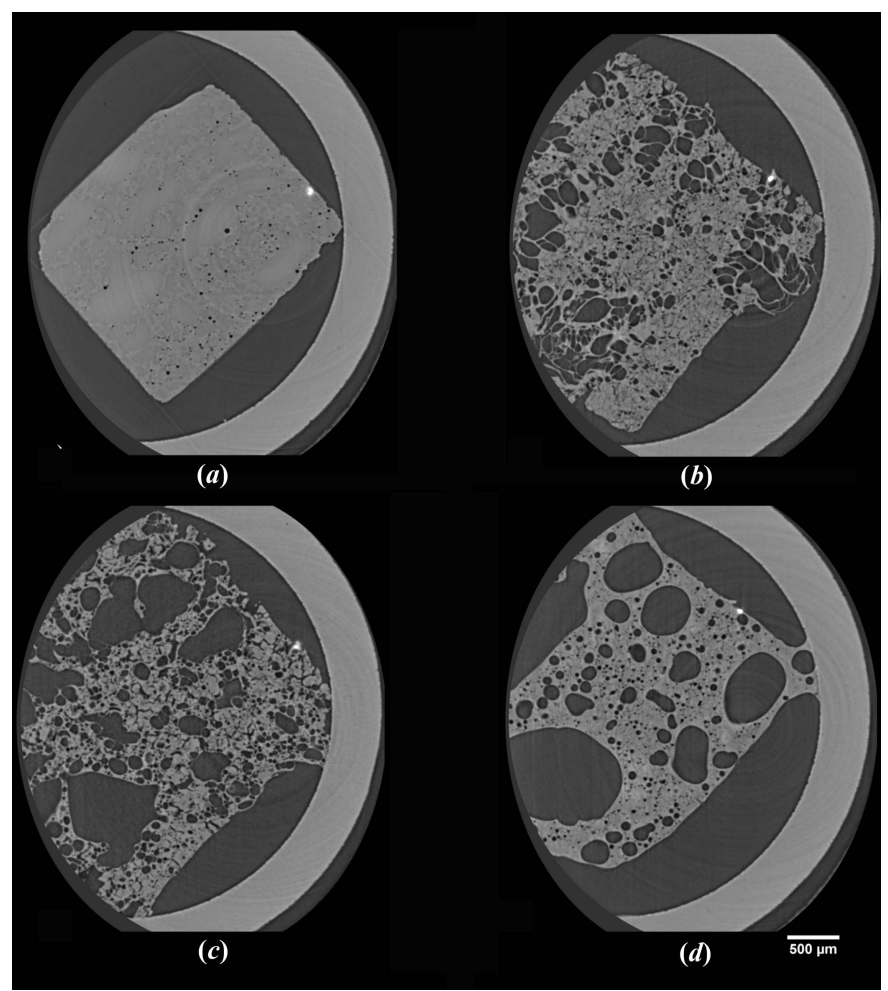

Figure 6

Region of interest selected from reconstructed axial slices of sample F60a after in situ X-ray $\mu \mathrm{CT}$ experiments performed at SYRMEP: $(a)$ at room temperature before heating, and at room temperature after quenching at (b) $1073 \mathrm{~K},(c) 1373 \mathrm{~K}$ and (d) $1673 \mathrm{~K}$. The sample was kept at the selected temperature for $10 \mathrm{~min}$ and then quenched by switching off the furnace. 


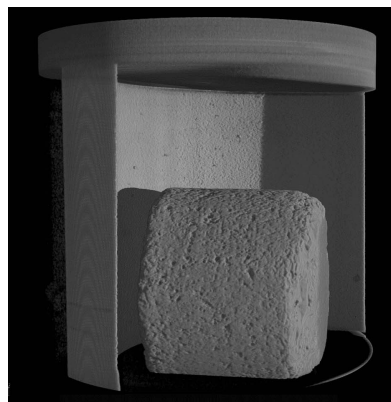

(a)

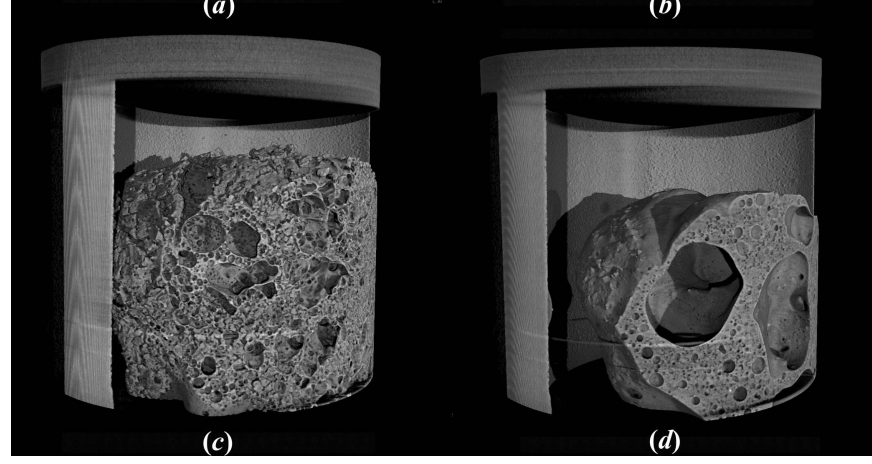

Figure 7

Volume renderings corresponding to cropped analyzed volumes of sample F60a at the same temperatures reported in Fig. 6 and for the same crop of the investigated sample volume.

ture (e.g. Giordano et al., 2008), and how such a viscosity decrease strongly controls the different stages of dynamic vesiculation textures, ranging from frothy bubbles $(1073 \mathrm{~K})$ to tubular structures made by connected bubbles $(1373 \mathrm{~K})$, and finally to large coalesced bubbles suspended in the crystalbearing melt (1673 K). These in situ and real-time experiments demonstrate the powerful approach of observing dynamic processes that volcanologists could only infer from postmortem microstructures and chemistry of already erupted volcanic samples. Indeed, the vesiculation dynamics of a volcanic sample has been captured with three consecutive sequences of radiographs collected during heating of sample F60a (see Movie S3 of the supporting information).

\section{Conclusions}

We introduce a compact and versatile induction furnace design for both ex situ and in situ time-resolved experiments at high temperatures (up to $1723 \mathrm{~K}$ ) using synchrotron and laboratory X-ray microradiography and microtomography. The furnace is specifically designed for applications in the fields of material and Earth sciences and its technical features were optimized for use at the SYRMEP beamline of Elettra in white beam mode. For this reason, and due to the photon flux presently available at the beamline, the induction furnace was designed to provide the necessary thermal conditions for high spatial resolution ( 1 to $3 \mu \mathrm{m}$ ) microtomographic analysis of dynamic processes compatible with total scan durations consistent with relatively slow phase transformations (e.g. melting and crystallization) and dynamic transport processes at high temperature. Faster processes such as vesi- culation in volcanic rocks and foaming of other materials can also be investigated using the same approach reported in this contribution.

The small size and high flexibility of the induction furnace allows its installation at other synchrotron beamlines or its use in an open instrument based on a microfocus X-ray source, such as the TomoLab station of Elettra. This ability will aid in the preparation of synchrotron-based experiments in terms of experimental parameters for image acquisition (X-ray energy, detector pixel size, sample-to-detector distance), temperature triggering for phenomena under study, and to establish convenient temperature ramps for the material of interest. This could be done by microradiography experiments or ex situ microtomographic experiments performed at different stages of the high-temperature treatment after quenching of the sample. Finally, in situ microtomographic experiments at lower spatial resolution could be also performed for a 'coarse' monitoring of the high-temperature treatments before synchrotron-based experiments at higher contrast and spatial resolution.

This novel high-temperature design opens up new frontiers of in situ characterization of materials and the processes forming them. Preliminary experiments performed on synthetic rocks and ceramic samples, exploring the abovementioned possibilities, show that most of the features of interest can be resolved and captured.

\section{Acknowledgements}

The authors are grateful to: B. Cordonnier (Nationaal Archief of the Netherlands), D. Dreossi (Elettra, Italy), F. Arzilli, M. Polacci (University of Manchester, UK) and the Linn High Therm GmbH staff (Germany) for useful discussions during the induction furnace design stage; M. Bregant (INTELLION, France) for support in the choice of materials for the furnace shell and sample holders; the Elettra staff for technical support during the commissioning phase of the instrument; A. G. Whittington (University of Missouri, Columbia, USA) for assisting MP during calorimetric measurements of the synthetic volcanic glass used in this study. The authors appreciated the editorial handling of the manuscript and the valuable comments received during the review process that helped to improve the paper.

\section{Funding information}

MP acknowledges the support of the Ambizione Fellowship of the Swiss National Science Foundation (PZ00P2-168166/1). Portions of this research were funded by a Discovery Grant from the Natural Sciences and Engineering Research Council of Canada (to DRB).

\section{References}

Bai, L. D. R., Baker, D. \& Rivers, M. (2008). Earth Planet. Sci. Lett. 267, 533-547.

Baker, D. R., Brun, F., O'Shaughnessy, C., Mancini, L., Fife, J. L. \& Rivers, M. (2012). Nat. Commun. 3, 1135. 
Bernasconi, A., Diella, V., Marinoni, N., Pavese, A. \& Francescon, F. (2012). Ceram. Int. 38, 5859-5870.

Bernasconi, A., Marinoni, N., Pavese, A., Francescon, F. \& Young, K. (2014). Ceram. Int. 40, 6389-6398.

Boller, E., Tafforeau, P., Rack, A., Fernandez, V., Helfen, L., Rénier, M., Valade, J. P., Vitoux, H., Villanova, J., Cloetens, P., Fayard, B., Guiraud, O. \& Latil, P. (2017). 3rd International Conference on Tomography of Materials and Structures (ICTMS), Lund (Sweden), ICTMS2017-66.

Bouttes, D., Lambert, O., Claireaux, C., Woelffel, W., Dalmas, D., Gouillart, E., Lhuissier, P., Salvo, L., Boller, E. \& Vandembroucq, D. (2015). Acta Mater. 92, 233-242.

Brown, G. H., Hoyler, C. N. \& Bierwirth, R. A. (1947). Theory and Application of Radio-Frequency Heating. New York: D. Van Nostrand Company.

Brun, F., Mancini, L., Kasae, P., Favretto, S., Dreossi, D. \& Tromba, G. (2010). Nucl. Instrum. Methods Phys. Res. A, 615, 326-332.

Brun, F., Massimi, L., Fratini, M., Dreossi, D., Billé, F., Accardo, A., Pugliese, R. \& Cedola, A. (2017). Adv. Struct. Chem. Imag, 3, 4-12.

Brun, F., Pacilè, S., Accardo, A., Kourousias, G., Dreossi, D., Mancini, L., Tromba, G. \& Pugliese, R. (2015). Fundamenta Informaticae, 141, 233-243.

Carty, W. M. \& Senapati, U. (1998). J. Am. Ceram. Soc. 81, 3-20.

Celik, H. (2010). Appl. Clay Sci. 50, 245-254.

Cloetens, P., Pateyron-Salomé, M., Buffière, J. Y., Peix, G., Baruchel, J., Peyrin, F. \& Schlenker, M. (1997). J. Appl. Phys. 81, 5878-5886. Curreri, P. A. \& Kaukler, W. F. (1996). Metall. Mater. Trans. A, 27, 801-808.

Daudin, R., Terzi, S., Lhuissier, P., Salvo, L. \& Boller, E. (2015). Mater. Des. 87, 313-317.

Deines, P., Nafziger, R. H., Ulmer, G. C. \& Woermann, E. (1974). Temperature-oxygen fugacity tables for selected gas mixtures in the system $\mathrm{C}-\mathrm{H}-\mathrm{O}$ at one atmosphere total pressure: Bulletin of the Earth and Mineral Sciences Experiment Station, edited by University Park: College of Earth and Mineral Sciences, 88, p. 129. Pennsylvania State University.

De Schryver, T., Dhaene, J., Dierick, M., Boone, M. N., Janssens, E., Sijbers, J., van Dael, M., Verboven, P., Nicolai, B. \& Van Hoorebeke, L. (2016). NDT \& E Int. 84, 89-98.

Feldkamp, L. A., Davis, L. C. \& Kress, J. W. (1984). J. Opt. Soc. Am. A, 1, 612-619.

Fife, J. L., Rappaz, M., Pistone, M., Celcer, T., Mikuljan, G. \& Stampanoni, M. (2012). J. Synchrotron Rad. 19, 352-358.

Giordano, D., Russell, J. K. \& Dingwell, D. B. (2008). Earth Planet. Sci. Lett. 271, 123-134.

Gualtieri, A. F. (2007). J. Am. Ceram. Soc. 90, 1222-1231.

Herman, G. T. (1980). Image Reconstruction from Projections: The Fundamentals of Computerized Tomography. New York: Academic Press.

Kak, A. C. \& Slaney, M. (1988). Principles of Computerized Tomographic Imaging. IEEE Press.

Larsson, D. H., Takman, P. A. C., Lundström, U., Burvall, A. \& Hertz, H. M. (2011). Rev. Sci. Instrum. 82, 123701.

Lavrenko, V. A. \& Alexeev, A. F. (1986). Ceram. Int. 12, 25-31.

Li, B., Brody, H. D., Black, D. R., Burdette, H. E. \& Rau, C. (2006). J. Phys. D Appl. Phys. 39, 4450-4456.
Maire, E. \& Withers, P. J. (2014). Int. Mater. Rev. 59, 1-43.

Marinoni, N., Pagani, A., Adamo, I., Diella, V., Pavese, A. \& Francescon, F. (2011). J. Eur. Ceram. Soc. 31, 273-280.

Mayo, S. C., Stevenson, A. W. \& Wilkins, S. W. (2012). Materials, 5, 937-965.

Miller, E. W. J. \& Beech, J. (1972). Metallography, 5, 298-300.

Mokso, R., Marone, F., Haberthür, D., Schittny, J. C., Mikuljan, C., Isenegger, A. \& Stampanoni, M. (2010). AIP Conf. Proc. 1365, 38 41.

Mokso, R., Schlepütz, C. M., Theidel, G., Billich, H., Schmid, E., Celcer, T., Mikuljan, G., Sala, L., Marone, F., Schlumpf, N. \& Stampanoni, M. (2017). J. Synchrotron Rad. 24, 1250-1259.

Nafziger, R. H., Ulmer, G. C. \& Woermann, E. (1971). Gaseous buffering for the control of oxygen fugacity at one atmosphere: Research Techniques for High Pressure and High Temperature, edited by Ulmer, G. C., p. 367. New York: Springer.

Paganin, D., Mayo, S. C., Gureyev, T. E., Miller, P. R. \& Wilkins, S. W. (2002). J. Microsc. 206, 33-40.

Pistone, M., Arzilli, F., Dobson, K. J., Cordonnier, B., Reusser, E., Ulmer, P., Marone, F., Whittington, A. G., Mancini, L., Fife, J. L. \& Blundy, J. D. (2015a). Geology, 43, 699-702.

Pistone, M., Caricchi, L., Fife, J. L., Mader, K. \& Ulmer, P. (2015b). Bull. Volcanol. 77, 108.

Pistone, M., Whittington, A. W., Andrews, B. J. \& Cottrell, E. (2017). J. Volcanology Geothermal Res. 347, 1-14.

Polacci, M., Baker, D. R., Mancini, L., Favretto, S. \& Hill, R. (2009). J. Geophys. Res. 114, B01206.

Polacci, M., Mancini, L. \& Baker, D. R. (2010). J. Synchrotron Rad. 17, 215-221.

Rack, A., Stiller, M., Dalügge, O. \& Knabe, C. (2009). Imaging Micros. 11, 32-34.

Riesch, J., Buffiere, J. Y., Höschen, T., di Michiel, M., Scheel, M., Linsmeier, C. \& You, J. H. (2013). Acta Mater. 61, 7060-7071.

Schindelin, J., Arganda-Carreras, I., Frise, E., Kaynig, V., Longair, M., Pietzsch, T., Preibisch, S., Rueden, C., Saalfeld, S., Schmid, B., Tinevez, J. Y., White, D. J., Hartenstein, V., Eliceiri, K., Tomancak, P. \& Cardona, A. (2012). Nat. Methods, 9, 676-682.

Sen, S., Curreri, P., Kaukler, W. F. \& Stefanescu, D. M. (1997). Metall. Mater. Trans. A, 28, 2129-2135.

Singer, F. \& Singer, S. S. (1963). Industrial Ceramics, pp. 99-100. London: Springer.

Tromba, G., Longo, R., Abrami, A., Arfelli, F., Astolfo, A., Bregant, P., Brun, F., Casarin, K., Chenda, V., Dreossi, D., Hola, M., Kaiser, J., Mancini, L., Menk, R. H., Quai, E., Quaia, E., Rigon, L., Rokvic, T., Sodini, N., Sanabor, D., Schultke, E., Tonutti, M., Vascotto, A., Zanconati, F., Cova, M., Castelli, E. \& Siu, K. K. W. (2010). AIP Conf. Proc. 1266, 18-23.

Wilkins, S. W., Gureyev, T. E., Gao, D., Pogany, A. \& Stevenson, A. W. (1996). Nature (London), 384, 335-338.

Yu, J. M., Wanderka, N., Rack, A., Daudin, R., Boller, E., Markötter, H., Manzoni, A., Vogel, F., Arlt, T., Manke, I. \& Banhart, J. (2017). Acta Mater. 129, 194-202.

Zandomeneghi, D., Voltolini, M., Mancini, L., Brun, F., Dreossi, D. \& Polacci, M. (2010). Geosphere, 6, 793-804.

Zhao, C., Fezzaa, K., Cunningham, R. W., Wen, H., De Carlo, F., Chen, L., Rollett, A. D. \& Sun, T. (2017). Sci. Rep. 7, 3602-3612. 